\title{
Research on Millimeter-wave Microstrip Patch Antenna Design for 5G
}

\author{
Madhan M D, Subitha D, Chandra I
}

\begin{abstract}
The objective of this article is to illustrate about the requirements of the patch antenna and to provide a short survey approximately the way to pick them. Seeing that $5 G$ is the ultra modern era in the upcoming communication systems, we focused on the millimeter wave frequencies with an intention to give more information about them. This paper additionally explains about the impact of numerous parameters such as substrate thickness, resonant frequency, various feeding techniques. different shapes of patch, millimeter wave frequency ranges etc.. on the antenna performance.
\end{abstract}

Keywords - Requirements of Microstrip patch antenna, Impact of substrate, Impact of dimensions of the patch, impact of thickness of the substrate, impact of various feeding techniques, impact of shape of the patch, impact of resonant frequency

\section{INTRODUCTION}

Millimeter wave is the band of range that is in between the microwaves and infrared (IR) waves, which is popularly defined as extremely high frequencies (EHF) that is well suited for 5G networks. They allows a transmission of frequencies from $30 \mathrm{GHz}-300 \mathrm{GHz}$. The wavelength is in the range of $1 \mathrm{~mm}-10 \mathrm{~mm}$. Millimeter wave allows to occupy more spectrum. Wireless data in the range of microwave frequency and lower than that are about $1 \mathrm{~Gb} / \mathrm{s}$. In the mm-wave range of frequency, the speed of data can reach up to $10 \mathrm{Gbits} / \mathrm{s}$ and more. Video signals are in need of the very high bandwidth and, also a large data rate. The data rates should be in gigabits (gb/s) to transmit HD (high definition) video (1080p). That speed of data can be minimized if the video techniques are utilized before the transmission. Later on, rate of data of many megabits $(\mathrm{mb} / \mathrm{s})$ can be transmitted efficiently. Millimeter-wave techniques can achieve huge gigabit of speed which is in return easy to get the work done. There is a sophisticated interest in enforcing a wireless version of USB 3.0. It's miles turning into the interfacing of desire now not only on computers, tablets however additionally Television(TV) sets and some other customer gear. The USB 3.0 specifies a maximum data rate of $5 \mathrm{gbits} / \mathrm{s}$ with approximately of $80 \%$ of that data rate being done in a practical application Patch antennas extensively called

microstrip patch antennas are in severe call for within the age

Revised Version Manuscript Received on 10 September, 2019.

Madhan M D, B.E. Scholar, Department of Electronics and Communication Engineering, Saveetha School of Engineering, Chennai, 602105, Tamilnadu, India.(Email: mdmadhan25@ gmail.com)

Subitha D, Assistant Professor, Department of Electronics and Communication Engineering, Saveetha School of Engineering, Chennai, 602105, Tamilnadu, India.(Email: subitharaj01 @ gmail.com)

Chandra I, Assistant Professor, Department of Electronics and Communication Engineering, Saveetha School of Engineering, Chennai, 602105, Tamilnadu, India.(Email: Chandra.rajagurugmail.com) of Wi-Fi and wimax applications. Researchers are doing to lot of efforts to make it slick, reliable and usable in these ranges. It has lot of benefits with positive limitations, which creates problems to meet the requirement possibilities and skills of this antenna. Patch antennas are available in specific shapes and sizes. Rectangular patch is maximum easy and easy to fabricate, but frequency requirement to meet the standards to have beneficial bandwidth, is reducing the size of it, which is likewise used to get an excellent directivity, advantage and efficiency. It is essential to design broadband antennas to cover a wide range of frequencies for the empowerment of wireless communication techniques and to meet the necessities in the communication system. The antenna size is too large to use in higher applications. So in view to reduce the size and cost of the antenna, the microstrip printed antennas were used. These printed antennas are more augmented and utilized because they are simple to fabricate on a circuit board. Printed antennnas are appealing mechanism for use in many applications due to their engrossing highlights such as low price, simple weight and reliability.

Planar microstrip antennas are very popular in the era of development of communication system from $3 \mathrm{~g}$ to $5 \mathrm{~g}$ structures. They play an vital function to enhance the bandwidth and make it extra narrow and modern to fit in communication. Microstrip lines or microstrip antennas are basically a component to develop the concept of planar geometry. Microstrip antennas are greater useful and in being used simply due to ease of fabrication and compatibility to alternate its structure in line with need and use. These patch antennas are capable of radiating the high frequency waves. These antennas can be operated in single and multiple band frequencies. This is one of the reason to make this antenna popular and has an extensive application in 5G communication systems using millimeter wave frequencies.

\section{LITERATURE SURVEY}

Quite a few studies is going at the destiny generation of mobile conversation. Many proposals in terms of architecture and generation have been given by means of one-of-a-kind authors and research groups around the sector along side addressing the issues, troubles that may occur in implementing those proposals. Brief overview of some of these studies work associated with this designs had been offered here contributing closer to the numerous antenna 
designs, with admire to the technologies that are without a doubt the key promising technology related to this new technology $5 \mathrm{~g}$.

The microstrip antennas had been studied appreciably for the duration of the beyond three many years. These antennas preferentially consists of a metallic patch revealed on a dielectric substrate over a ground plane, gives many blessings which includes ease of layout and fabrication, low profile. In current years, with the dynamic changes of new standards and sophisticated Wi-Fi gadgets, there is a need developed to reduce the appearance of these type of microstrip patch antennas. These miniaturization strategies involves changing the shape of antenna, material inserting, folding, inserting slots and defects inside the ground plane. The foremost characteristics and downsides of these techniques are highlighted in this paper [1].

The defects of different sizes and shapes in the ground plane of patch antenna improves the technical parameters like VSWR, return loss, performance and so on. This has been carried out by using analyzing and experimenting by means of slicing different shapes of defects within the ground of antenna. Authors are recommending the micro strip patch antenna for Wi-Fi frequency in this paper. The performance and features of micro strip antenna includes cost price is low, short profile, less in weight made them best desire for communication systems engineers [2].

A unique layout of mm-wave micro strip patch antenna in broadband for gadgets like mobile has brought various changes in the $5 \mathrm{G}$ communication system. In this paper, the author proposes an antenna detail that operates around 40 GHz. 9 percent of bandwidth can be obtained by using more than one resonance patch structure.In this paper, the author says that parasitic patches are carried out to lessen the antenna's directivity, and thus develops the microstrip patch antenna appropriate for targeted cell features [3].

While compared with $4 \mathrm{~g} / 3 \mathrm{~g} / 2 \mathrm{~g}$ communication technologies, the close to destiny $5 \mathrm{~g}$ wireless verbal exchange mechanisms can also develop $60 \mathrm{GHz} \mathrm{mm}$-wave band as certainly one of the essential resonating frequencies for the benefits of high possible rate of transmission and broad bandwidth. In this article, the writer proposed a unique shape in designing an antenna array which is operated at the crucial frequency of $60 \mathrm{GHz}$. The complete antenna is adopted by means of 4 similar branches in which each one among is developed by using three rectangular patches which are linearly serialized. As a end result, the optimized microstrip antenna array can attain the gain of $8.4 \mathrm{dBi}$ at a frequency range of $60 \mathrm{GHz}$ [4].

This article reveals that there is a technique for fabrication of mm-wave patch antennas which is totally depends on the Printed Circuit Boards (PCB). The design of this technique had been authenticated for more than one layer printed patch antennas, displaying in all cases an accurate level appropriate for the manufacturing of mm-wave printed patch antennas [5].

There is sophisticated study in the area of micro-strip patch antennas within the latest years. This assessment gives the details of the task completed on printed antennas from the past ten years. Exclusive microstip patch antenna designs had been revealed with the point of interest in developing the microstrip patch antenna parameters like gain, efficiency, directivity, bandwidth and return loss. More research had done to fabricate these printed antennas highly compactable and occasional profile [6].

The layout of this rectangular printed patch antenna is resonated at $1.7 \mathrm{GHz}$ of frequency. These printed antennas are having very minimum profile and very simple to design. With the assist of defected shape mechanism, the given antenna has a medium return loss of $-33 \mathrm{db}$, better gain of $10 \mathrm{db}$ with suitable bandwidth of $109.4 \mathrm{MHz}$, the directivity is mentioned as 4.442 and ovwerall high performance of $90.95 \%$. Moreover, This antenna is reasonably-priced, low in size, simple to manufacture and compact [7].

This article represents about a microstrip patch antenna in rectangular shape using the defected ground plane method. The antenna is designed at broad bandwidth of 5GHz. The defected ground plane mechanism is used to increase the bandwidth of the antenna. In this, the duroid substrate is used which has dielectric constant of 2.2. The vswr value which is obtained in this antenna is less than 2 [8].

There are various shapes for the design of patch antenna. The traditional shapes such as circle, rectangle, triangle patch antenna represented in this paper. The $\mathrm{x}$-band range lies between $8 \mathrm{GHz}$ to $12 \mathrm{GHz}$ and has wide applications in radar. FR-4 is used as substrate in this paper [9].

A round disc shaped antenna which has a miniaturized layout has explored in this noval for wireless communications. Revealed on a dielectric substance and supplied via 50ohms microstrip line, the represented antenna has an capability to offer a very high extensive return loss of $10 \mathrm{db}$ bandwidth with better characteristics. The unique design decreases the occupied volume and it's far used to determine the parameters of the antenna [10].

\section{IMPACTS ON ANTENNA DESIGN}

Generally, the patch antenna consists of many components in it. Among them, the top layer which is patch, the middle layer that is the substrate and the botton one which is ground layer are the most important. The following are some vital impacts that influences the design of printed antenna.

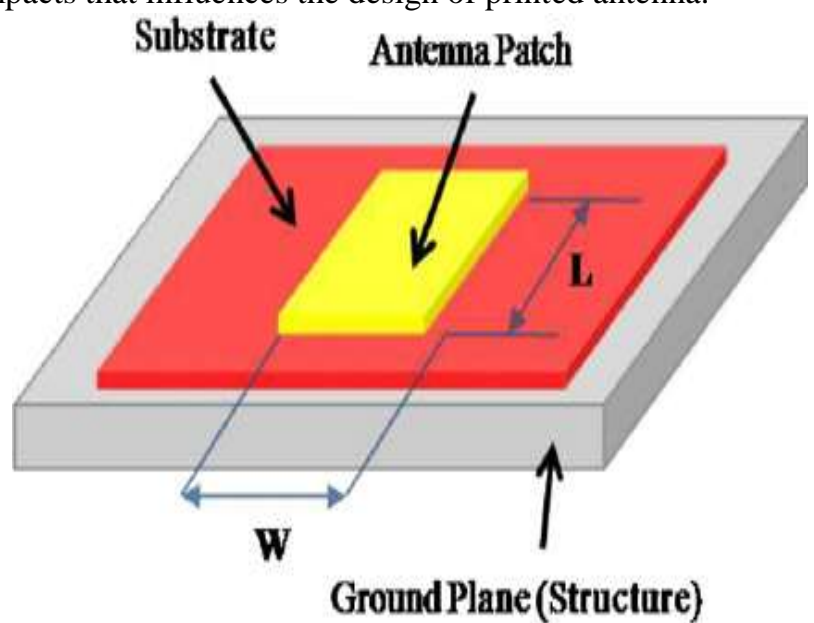

Figure.1 Perspective View

Blue Eyes Intelligence Engineering

\& Sciences Publication 
To manufacture and analyze a microstrip printed antenna the subsequent are the necessities:

- Selection of substrate type

- Substrate thickness

- Selection of patch shape

- Determining the Dimension of patch

- Type of Feeding mechanism

- Centered frequency

\section{i. Impact of Substrate:}

To obtain smart output for the given input, a substrate should be selected such that it should have a low dielectric value which is necessary since it provides effective bandwidth, medium range of radiation and desirable efficiency. Generally the dielectric value of the substrate is selected in the range of $2.1 \leq \varepsilon_{\mathrm{r}} \leq 12$ respectively.

The most popularly used dielectric substrates are

\section{a) FR-4 Substrate:}

FR-4 is a glass reinforced and epoxy laminated material. FR-4 glass epoxy is a versatile material which contains a fiber glass cloth (along with an epoxy resin binder) which is self-extinguishing. With nearly very low(approximately zero) water absorption, this substrate is highly popular as an electric insulator owning widespread physical strength. It has a dielectric value of 4.2 and a loss tangent of 0.008 respectively.

\section{b) RT Duroid:}

RT Duroid is an Glass Microfiber (Reinforced PolyTetraFluoroEthylene material) which showcase very high chemical resistance, along with some solvents that are utilized in printing mechanisms as well as fabrication processess such as slicing, machining. It has a dielectric value of 2.2 and loss tangent value of 0.0013 respectively.

\section{c) Cuflon:}

Cuflon consist of high composite of Teflon which is electroplated along with a copper material using a method evolved by means of polyflon. The device existence is predicted while extracting cuflon than glass laminates (reinforced). It has a dielectric value of 2.1 and loss tangent value of 0.0004 respectively.

\section{d) Fused quartz:}

Fused quartz also called as Fused silica is a glass together with silica which is not in crystalline shape. This property of substrate is an advanced one compared to some other variety of glass. The thermal expansion of this substrate is very low. It has a dielectric value of 3.78 and loss tangent value of 0.0001 respectively

\begin{tabular}{|l|l|l|l|}
\hline S.No & Type of Material & Dielectric Constant & Loss Tangent \\
\hline 1 & ABS (plastic), Molded & $2.0-3.5$ & $0.00500-0.0190$ \\
\hline 2 & Polyethylene LDPE/HDPE & 2.26 & 0.0031 \\
\hline 3 & Polycarbonate, Molded & $2.8-3.4$ & $0.000660-0.0100$ \\
\hline 4 & Polystyrene & $2.5-2.6$ & 0.00033 \\
\hline 5 & $96 \%$ Alumina & 9.4 & 0.0010 \\
\hline 6 & Silicon & $11.7-12.9$ & 0.015 \\
\hline 7 & Teflon (PTFE) & 2.1 & 0.00028 \\
\hline 8 & Sapphire & $9.4,1.6$ & 0.0001 \\
\hline 9 & Tefzel & $2.6-2.3$ & $0.0007-0.0119$ \\
\hline 10 & GaAs & 12.90 & 0.00200 \\
\hline
\end{tabular}

Table 1 Electrical proper ties of popularly utilized substrate composites for microstrip printed antennas

\section{ii. Impact of substrate thickness:}

Substrate thickness is one of the important parameters which is used to find out the dimension of the printed antenna. By increasing the height of the substrate(hs) to certain value improves the fringing fields of the antenna. Thereby, the expected outcome which is the radiation also increased extensively.
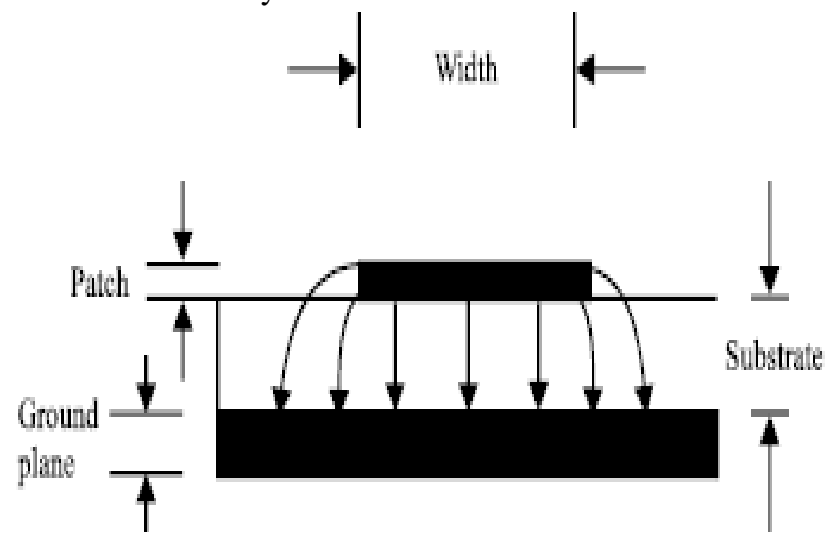

Figure.2 Fringing fields of the antenna iii. Impact of shape of the patch:

In order to obtain good outcome of the antenna, generally square, triangle, ring, rectangle, circle, triangle, and ellipse shapes are used for manufacturing a microstrip printed antenna. The fringing fields varies from one shape of patch to the another. The shape of the patch sometimes increases or decreases the size of the antenna. The shape of the antenna patch act as the aperture for the antenna in which the electromagnetic waves radiates along the edges of aperture of the antenna. Actually, there are different shapes of patch to sophisticate the radiation efficiency in which each patch have a different aperture, different values of dimensions to improve the gain of the antenna 

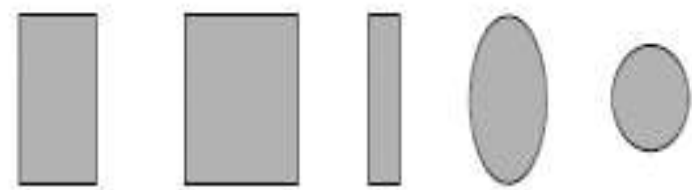

(2) Syen: (b) Rktangi:
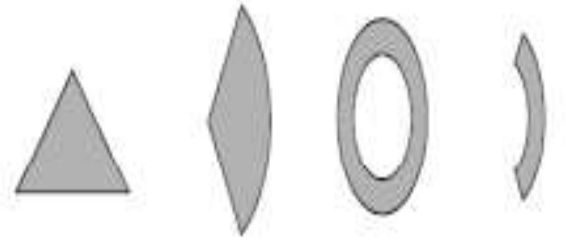

(A) Ting

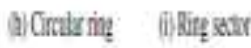

\section{Figure.3 Different shapes of the patch}

\section{$i v$. Impact of dimensions of the patch:}

The dimensions of patch of the antenna is highly based on the desired shape of the patch. There are different parametric calculations for different shapes. In general, for a rectangle shaped patch antenna, the length $\left(\mathrm{L}_{\mathrm{p}}\right)$ and width $\left(\mathrm{W}_{\mathrm{p}}\right)$ of the patch are the most essential parameters that are to be determined. The width of desired patch $\left(\mathrm{W}_{\mathrm{p}}\right)$ mainly depend on the centered frequency $\left(f_{r}\right)$ and its dielectric value $\left(\varepsilon_{r}\right)$. The length of the patch depends on the constant dielectric value of the $\operatorname{substrate}\left(\varepsilon_{\text {reff }}\right)$, constant length(Leff) and the length extension $(\Delta \mathrm{L})$ which additionally includes the values of width of desired patch $\left(\mathrm{W}_{\mathrm{p}}\right)$, height of the selected substrate(hs) and dielectric value of the substrate $\left(\varepsilon_{\mathrm{r}}\right)$ in its calculations.

For example, the following are the steps to calculate the Length and Width of the rectangular patch antenna:

Step 1: Calculation of constant Width (W):

$\mathrm{W}=\mathrm{c} / 2 * \sqrt{ }\left(2 / \varepsilon_{\mathrm{r}}+1\right)$

Step 2: Calculation of Effective and invariable Dielectric $\operatorname{value}\left(\varepsilon_{\text {eff }}\right)$ :

$\varepsilon_{\text {eff }}=\left[\left(\varepsilon_{\mathrm{r}}+1\right) / 2\right]+\left(\left(\varepsilon_{\mathrm{r}}-1\right) / 2\right) *[1+(12 * \mathrm{~h} / \mathrm{W})]^{\wedge}(-1 / 2)$

Step 3: Calculation of Effective and constant length (Leff): $\mathrm{L}_{\text {eff }}=\mathrm{c} /\left(2 \mathrm{f} \sqrt{ } \varepsilon_{\text {eff }}\right)$

Step 4: Calculation of Length of Extension of the patch $(\Delta \mathrm{L})$ :

$\Delta \mathrm{L}=0.412 \mathrm{~h} *\left[\left(\varepsilon_{\mathrm{eff}}+0.3\right) *((\mathrm{~W} / \mathrm{h})+0.264)\right] /\left[\left(\varepsilon_{\mathrm{eff}}-\right.\right.$ $0.258) *((\mathrm{~W} / \mathrm{h})+0.8)]$

Step 5: Calculation of resonant length of the patch (L):

$\mathrm{L}=\mathrm{L}_{\text {eff }}-2 \Delta \mathrm{L}$

\section{v. Impact of the feeding technique:}

Micro strip printed antenna is operated by distinct feeding mechanisms such as micro strip line feeding, proximity coupled feeding, coaxial feeding, and aperture coupled feeding. Among all the feeding mechanisms the micro strip line feeding is considered as the most easiest one to operate the antenna.The following table gives a clarity about the various feeding methods

Table 2 Types of feeding methods and its advantages, disadvantages

\begin{tabular}{|c|c|c|}
\hline Feeding techniques & Advantages & Disadvantages \\
\hline Microstrip line feeding & $\begin{array}{l}\text { 1. Easy to fabricate. } \\
\text { 2. Impedance matching is easy. }\end{array}$ & $\begin{array}{l}\text { 1. Bandwidth is low. } \\
\text { 2. High Cross polarization. }\end{array}$ \\
\hline Coaxial line feeding & $\begin{array}{l}\text { 1. Easy to fabricate. } \\
\text { 2. Low spurious radiation. }\end{array}$ & $\begin{array}{l}\text { 1. Bandwidth is low. } \\
\text { 2. High Cross polarization. }\end{array}$ \\
\hline $\begin{array}{l}\text { Proximity coupled } \\
\text { feeding }\end{array}$ & $\begin{array}{l}\text { 1. Low cross polarization. } \\
\text { 2. High bandwidth. } \\
\text { 3. Low spurious radiation }\end{array}$ & $\begin{array}{l}\text { 1. Difficult to fabricate. } \\
\text { 2. Cost is very high. }\end{array}$ \\
\hline Aperture coupled feeding & $\begin{array}{l}\text { 1. Low cross polarization. } \\
\text { 2. Moderate spurious radiation. }\end{array}$ & $\begin{array}{l}\text { 1. Difficult to fabricate. } \\
\text { 2. Narrow bandwidth. }\end{array}$ \\
\hline \multicolumn{3}{|c|}{$\begin{array}{l}\text { vi. Impact of resonant frequency: } \\
\text { The first attention to be made in designing any microstrip } \\
\text { antenna is to ascertain the size for any particular mode of } \\
\text { operation. The approach used for designing the antenna ought } \\
\text { to no longer handiest be able to predict correctly the } \\
\text { fundamental centre frequency. Commonly the centre } \\
\text { frequency of a printed antenna has a reactance that is } \\
\text { approximately equal to zero. } \\
\text { For } 5 \mathrm{G} \text { communication [11-13], the resonant frequency is }\end{array}$} \\
\hline
\end{tabular}




\section{IV.CONCLUSION}

In the above work, the various impacts on the antenna has been discussed. As per our survey, generally the micro strip patch antenna provides low bandwidth, low gain of nearly $5-6 \mathrm{~dB}$, and thereby it provides low efficiency. So in order to improve these characteristics there are certain bandwidth and efficiency enhancement methods like Defected Ground Structure technique, making slots in the ground, slicing the corners of patch etc are available. The role of DGS in the area of microwave and printed antennas is represented with numerous advances of DGS which involves multiple band bandwidth improvement, gain enhancement, cross-polarization suppression, higher mode harmonics suppression, and circular polarization achievement. Considering the above mentioned impacts, our further aim is to develop an high gain efficient antenna which can provide $5 \mathrm{G}$ communication using the millimeter wave frequencies

\section{REFERENCES}

1. Muhammad Umar Khan, Mohammad Said Sharawi, Raj Mittra, "Micro strip patch antenna miniaturization techniques: a review", IET Microwaves, Antennas \& Propagation, vol. 9, pp. 913-922, 2015.

2. Efficiency Enhancement Using Various Types Defected Ground Structures for Micro strip Patch Antenna International Journal of Advanced Engineering Research and Applications (IJA-ERA) ISSN: 2454-2377 Volume 2, Issue -3 , July -2016

3. Wang Kun, Kornprobst Jonas, Eibert F. Thomas, "Microstrip fed broadband $\mathrm{mm}$ wave patch antenna for mobile applications", 2016 IEEE International Symposium on Antennas and Propagation (APSURSI), pp. 1637-1638, 2016.

4. Ge Zhang, Shi Pu, Xiaoying Xu, Yuan Liu, Chen Wang, "Design of 60-GHz Microstrip Antenna Array Composed through Circular Contour Feeding Line", 7th Asia Pacific International Symposium on Electromagnetic Compatibility I, vol. 01, pp. 1010-1013, 2016

5. I. Venneri, A. Borgia, L. Boccia, G. Amendola, G. Di Massa, "Millimeter waves patch antenna design and realization on BCB polymer substrates" in 2014 IEEE xplore publications/Giuseppe_Di_Massa/publication.

6. Navreet Kaur; Shivani Malhotra, "A review on significance of design parameters of microstrip patch antennas"in 2016 IEEE Conference publications pages(1-6).

7. An Efficient Patch Antenna in Rectangular Shape by using Defective Ground Structure International Research Journal of Engineering and Technology (IRJET) e-ISSN: 2395 - 0056 Volume: 03 Issue: 05 | May-2016 www.irjet.net pISSN: 2395-0072

8. Bandwidth Enhancement in Microstrip Rectangular Patch Antenna using Defected Ground plane International Journal of Science, Engineering and Technology Research (IJSETR), Volume 4, Issue 11, November 2015

9. Comparison of different shapes in microstrip patch antenna for X-band applications", International Conference (ICETT), pp. 1-6, 2016.

10. Zuhura Juma Ali, "A Miniaturized Ultra Wide band (UWB) Antenna Design for Wireless Communications" International Journal of Scientific \& Research Publications, Vol 4, Issue 7, July 2014.

11. Subitha, D, Mathana, JM 2018, 'Design of Low ComplexityHybrid Precoder and Inkjet Printed Antenna Array for Massive MIMO Downlink Systems', Hindawi, International Journal of Antennas and Propagation, DOI: https :// doi. org/ 10. $1155 / 2018 / 4315128$.

12. Subitha, D , Mathana, JM 2018, 'A Novel Low Complexity Downlink linear precoding Algorithm for Massive MIMO Systems', Springer, Journal of Cluster Computing,

DOI: https://doi.org/10.1007/s10586-018-2050-1.

13. I. Chandra, N. Sivakumar, Chandra Babu Gokulnath, P. Parthasarathy, 'IoT based fall detection and ambient assisted system for the elderly', Cluster Computing https://doi.org/10.1007/s10586-018-2329-2 